\title{
Introduction to Selected Contributions from the 50th US Rock Mechanics/Geomechanics Symposium Held in Houston, Texas, from June 26 to 29, 2016
}

\author{
Azra N. Tutuncu ${ }^{1}$
}

Published online: 16 November 2017

(C) Springer-Verlag GmbH Austria 2017

This special issue of Rock Mechanics and Rock Engineering includes seven articles that are invited contributions from the 50th US Rock Mechanics/Geomechanics Symposium held in Houston, Texas, from June 26 to 29, 2016. The symposium is a focal multidisciplinary international annual event organized by the American Rock Mechanics Association (ARMA) to promote interactions and share recent technology developments among rock mechanics and geomechanics specialists, industry implementers and academicians.

The technical sessions at the symposium extended over a range of topics from petroleum, mining and civil engineering as well as multidisciplinary subjects involving expertise from many areas of engineering and geosciences, bringing fundamental research findings through integrating analytical and numerical modeling, laboratory experiments and field case studies and highlighting the unique role of geomechanics in these multidisciplinary applications.

The papers contained in this special issue were selected by members of the Organizing Committee of the 50th US Rock Mechanics/Geomechanics Symposium based on the quality of their technical content. Special thanks are due to Karim Zaki for his contribution during the early stages of the review process. All invited papers were first expanded and rewritten and then were peer reviewed using the standard procedures of the RMRE journal prior to publication in this special issue.

The articles presented address a wide range of topics from geotechnical classification and scale-dependent fracture stiffness to unconventional reservoir production optimization with unique geomechanics and rock engineering experimental, field and/or modeling results.

Azra N. Tutuncu

atutuncu@mines.edu

1 Petroleum Engineering Department, Colorado School of Mines, 1500 Illinois St., Golden, CO 8040, USA 